\title{
State Sponsored Bioterrorism: An Instant Need to Develop Counter Action Strategies and Safety Options for Future
}

\section{R K Upadhyay*}

Department of Zoology, Deen Dayal Upadhyaya Gorakhpur University, Gorakhpur, $U P$, India

*Corresponding Author: R K Upadhyay, Department of Zoology, Deen Dayal Upadhyaya Gorakhpur University, Gorakhpur, UP, India.

\section{Received: May 28, 2021}

Published: June 24, 2021

(C) All rights are reserved by $\mathbf{R} \mathbf{K}$ Upadhyay.

\begin{abstract}
Present article explains major threats generated by bioterrorism, risks, and its devastation impact on human life. This article also highlights different bio-weapons or genetically modified micro-organisms, methods of bio-defense, bio-security, surveillance and other strategies to counter attack the bio-weapon dissemination. Terrorists can disseminate these HMMOs in the environment to take revenge from states. Their mental temper is to cause widespread fear and panic among the people beyond the actual social, physical, economic damage and destruction of living environment. Biological agents multiply very fast once they open in the environment and infect people in masses and show high multiplication in affected people. Within few days they cause large numbers of fatalities in comparison to any naturally occurring disease. It seemingly put longer implications on society, economy and biological life of an affected country. Therefore, fast counter safety is highly essential to slow down deadly fission or chain of microbes like radioactive wombs. These high-priority agents pose a risk to national security and must require special action for public health preparedness to minimize or breakdown deadly impact of microorganisms by making safety vaccines for immunization, antimicrobial drugs, sera, antibodies and all other prophylactic and safety measures. Further, to mitigate the effect of any virus, bacterial, fungal, protozoan attack, special microbial disease prevention centers and clinical aid centers must be established with all possible equipments and clinical aids. These are more essentially required for the safety of citizens of every sovereign country. This should be included in national security advisory and priority list to create fast acting operational groups in wartime. Covid-19 caused by SARS-CoV-2 is a China made virus, it has many features similar to a biological weapon.
\end{abstract}

Keywords: Bio-terrorism; Threats; Mutually Deterrent World (MDW); Human Modified Mass Multiplying Microorganisms (HMMOs); Non-confronting Countries (NCCs); Prophylactic and Safety Measures

\section{Introduction}

Today global terrorism is a rapidly growing threat to world security, and increases the risk of bioterrorism. Due to development of genetic engineering methods, fast replicating micro-organisms or biological agents have been modified for various purposes. But terrorists groups have used these genetically modified organisms as biological weapons. These are highly destructive silent weapons which cause major devastation if inoculated once in a very short time. These may be used by terrorists as an undeclared war in future; it has forced the developed nations to prepare counter strategies to defy any microbial attack if it may suddenly provoke. Today, the entire world is passing through state sponsored pandemic, it is 
well designed and spread in form of a secret mission to destabilize the world economy by the Chinese army. This is very much unfortunate that states are behaving with the peaceful world like terrorists. This is not good sign and signal for entire humanity on existing on planet earth. However, in mutually deterrent world (MDW) use of nuclear weapons could be reduced to minimum by modifying the political and diplomatic ways through treaties and amending new safer policies. But deliberate release or dissemination of biological agents will be more disastrous and dangerous than the nuclear weapons. It is more dangerous and finding its cause of spread is very difficult. However, the possibility of use of microbes of some dreadful diseases like anthrax, botulism, plague, smallpox, and tularemia as bio-weapon has been increased.

Terrorists are trying to obtain methods to cultivate microorganisms of anthrax, small pox, and plague and botulism toxins in the laboratory. Terrorists can use these genetically modified/human modified mass multiplying microorganisms (HMMOs) against nonconfronting countries (NCCs) without any reason and only due to their revengeful act of hatred or in the name of religious war [1]. In future these pathogens could be used by state sponsored bioterrorism as highly destructive biological weapons. However, smaller bombshells of fast growing deadly microbes may release in environment in revengeful manner. These spread very fast, show high infectivity and do large numbers of deaths unknowingly. These also evoke due to natural climatic conditions and cause severity much lesser than any bio-weapon. Similarly, viruses that cause hemorrhagic fevers, such as Ebola, Marburg, Lassa, and Machupo disease agents exist in nature (except for smallpox, which has been eradicated in the wild), but they could be manipulated to make them more dangerous [1].

Bioterrorism or biological warfare is an emerging threat to human society, and microbial disease pathogens agents of disease may be used for hostile purposes [2]. However, deliberate release of viruses, bacteria, or other agents will cause illness or death in people, animals, or plants by terrorists. Biological agents are multiply very fast and causes more deaths in comparison to any direct war have longer implications on society, economy and biological life of the country. The main target of terrorists is mainly to destabilize economic, political, social frame work and damage religious value Future terrorists attack will be more lethal and cane cause huge damage and devastation of human life in any corner of the world, or can target whole world as well [3]. Bioterrorism is posing global threat due to ongoing geopolitical conflicts. Terrorists can cause high mortality and major impact on public health, naturally occurring infectious diseases cause moderate morbidity [4]. However, to stop insurgence and foster the counter attack and effect of bio-weapons development of new vaccines and antimicrobial therapies are highly essential. These must be included in priority list, and for prior bio-defense will need to expedite clinical trials using new methodologies [5]. Further, to stop such activities Biological and Toxin Weapon Convention be formed and terrorist hide out must be finished on the basis of proof. Bioterrorism must be countermanded at any cost to save the entire world from any deliberate use of biological warfare agents in future [6].

\section{Biological weapons}

Bio-weapons are unusual and dangerous pathogenic agents mainly of zoonotic origin could be used [7]. Use of bio-weapons is most heinous act and crime against human race and humanity. These biological agents are bacteria, viruses, or toxins. It may be operated in a naturally occurring or a human-modified form and kill large number of people. Terrorists can disseminate them to take revenge or the desire for monetary gain by extortion, rather than by political, ideological, religious or other beliefs [6]. Microbial origin biotoxins are potentially used to produce illness, death and terror [8]. There are six most dangerous toxins: botulinum toxin, Staphyococcal enterotoxins, Clostridium perfringens toxins, ricin, abrin and T-2 toxin have been reported so far [8]. After 2001, terrorists used Anthrax spores very silently and attacked US by sending them through postal letters. It was a deliberate attack, B. anthracis spread was more dangerous, it has created panic all around and but early investigation check the outbreak of disease [9]. Anthrax is an infectious fatal disease with epidemic potential. After reports of the intentional release of Bacillus anthracis in the United States, epidemiologists, laboratorians, and clinicians around the world were called upon to respond to widespread political and public concerns [10]. Team of microbial forensics have identified BW, BT, and BC in biological samples [11]. After 9/11 attack societies feel so vulnerable and largely speculate the repetition of past scenarios of bioterrorism [12]. Though, this threat was neutralized in a very short time due to amid alertness and vaccination of the people before its spread [13]. US defense laboratories very quickly detected the presence of these deadly microbes in contaminated 
mails or environmental materials and an alarm was raised not to handle suspicious letters for safety and security. To mitigate the effect and cut down panic from public testing specimens from acutely ill patients and also being asked to test nasal swabs from the potentially exposed persons may prove much better [14]. It was strictly followed after October 2001 attack in US [14].

This is the dark side of human race on earth that they have grown enmity in between, the reasons are many more. It has been converted into racial, religious and territorial conflicts, and generated well organized terror and unmanageable losses done by terrorists. They can disseminate biological agents intentionally in public places, chances of it's has been increased due to rising enmity among states [3]. There is much possibility of falling unpredictable attacks in future without any verbal or written threats from any terrorist group. These are possible by simple spray devices, small bombshells, postal letters, food pickings' and toys which remain unclaimed by a terrorist group that they have released a biologic agent. Sudden release of microbial warfare agents, will cause widespread public panic and lead to contamination of soil, water, air, clothing and food commodities. It will unfortunately generate major devastation to human society, mass numbers of untimely death and economic and political losses.

In comparison to other conventional weapons biological weapons are low cost and ease of access and need no special technology to launch. Its detection is very difficult because of silent attack, once used, disease pathogens persists for longer time. These unusual, unreliable, advanced, cause unpredictable casualties need no specific delivery systems. After dissemination microbes used in bio-weapon cause high morbidity and mortality, spread through air from person-to-person spread. Its air suspending aerosols or low infective dose reamins out of diagnostic tests. These show environmental stability and cause rapid decline in environmental quality that leads to an increase in biohazards. From the sources of investigation agencies most of the recent viruses coming out of China some form of bio-weapons. However, uncontrolled bird flu, dengue and recent pandemic of corona virus are microbial war fares. It is important to address bioterrorism at every forum so that sustainable solutions can be devised to tackle environmental deteriorations [2].

\section{History of biological warfare}

There are so many episodes of biologcial warfare happened inthe past. There are so many evidences exist even today about use of microbial pathogens as bioweapns in war or terrorism from ancient times. A fungus Calviceps purpurea (rye ergot) was used for poisoning the water supplies in the sixth century B.Cassyrians. A Mongol army besieged the Genoan trading outpost at Caffa in the Crimea (1346-1347) suffered an outbreak of the plague, apparently of natural cause. Later on plague arrived in the Genoans, Naples and then Genoa, from where the plague spread throughout Europe. But all these attacks were unorganized and sporadic but killed large number of people. There are archives available on use of smallpox contaminated blankets by the British army to the Native American population loyal to the French in 1767. All these events caused large mortality of soldiers.

The Japanese used plague as a biological weapon during the Sino-Japanese War in the late 1930s and 1940s. They filled bombs with plague-infected fleas and dropped them from airplanes onto two Chinese cities. These were having cholera and shigella microbes in small bombshells as weapons in other attacks. In 1969, U. S. unilateral decision to destroy bio-weapons. In World War II countries i.e. U.S, Canada, Great Britain, Japan, and the U.S.S.R experimented with anthrax. In 1972, Bio-weapons Convention organized in which U. S. and U. S. S. R. were signed to foster and check possible/probable active offensive bio-weapons programs in $\mathrm{N}$. Korea, Iran, China, Egypt, Algeria, India, Pakistan, Syria and Israel. In 1991, Iraq threatens use of bio-weapons against U. S. troops in Persian Gulf War. The U.S. Department of Homeland Security and other several groups have analyzed such threats. The National Biodefense Analysis and Countermeasures Center (NBACC) examined and established the scientific basis of the risks posed by biological threats. NBACC's National Biological Threat Characterization Center (NBTCC) conducts studies and experiments on current and future biological threats. It also assesses vulnerabilities and does risk assessments and determines potential impacts to guide the development of countermeasures such as detectors, drugs, vaccines, and decontamination technologies. For a regulatory control the Biological and Toxin Weapons Convention (BTWC) came into force in 1975. Its main aim is to finish the development and production of bio-weapons. More than 100 nations, including the United States, have signed this international treaty. It is true, despite the agreement, bio-weapon threats from fringe groups, terrorists, and nations not committed to or observing the convention continue to worry public health authorities. 


\section{Routes of entry}

Micro-organisms may enter inside human body through inhalation, ingestion, dermal or skin penetration. These could be mixed in food, water supply, gifts, clothing, capsules and swabs. In bioterrorism highly visible and photogenic micro-organisms are used, which cause asymmetric attack and results in large number of deaths in short time. Without causing any symptom these are transferred from person to person through inhalation. In most cases symptoms remain non-specific and remain non-diagnosable and show complex epidemiology.

\section{Classification}

Centers for Disease Control and Prevention (CDC) classifies potential biologic threats into three categories: A, B, and C. The category A includes pathogens which can be easily disseminated or transmitted from person to person, cause high mortality and put major public health impact, create panic among people and society. These require require special action for public health preparedness (Table 1). Category B agents include those that are moderately easy to disseminate, result in moderate morbidity rates and low mortality rates, and require specifically enhanced diagnostic capacity. Category $\mathrm{C}$ agents include emerging pathogens the general population lacks immunity, could be engineered for mass dissemination in the future because of availability, ease of production, ease of dissemination, The recent emergence of novel viruses leading to outbreaks of severe acute respiratory syndrome (SARS), Nipah, hantavirus are examples (Table 1).

How to tackle the problem

\section{Biodefense and biosafety}

Bioterrorism is a very heinous crime against humanity, it is worst of part of a war silent cold invasion that devastate human values, culture and society at large scale. Biodefense represents the range of public health responses that can prevent or mitigate the effects of bioterrorism and of outbreaks of naturally occurring, emerging infectious diseases. It involves use of ready medical measures to protect against biological agents. Among important approaches of biodefense are fast detection of potentially harmful agents in the environment, its type, area of spread, and probability of its devastation. Biodefense is a technological logistic and quick responding photo-imaging system, detection equipments and counter acting, methods, devices which could mitigates the effects of bio-weapons in environment. Bio-weapons cause more devastation than naturally occurring, emerging infectious diseases [4]. There should be syndromic surveillance of disease outbreak, affected people and possible treatment methods under application. Therefore, early warning systems are required to stop the chain of GMOs which cause microbial diseases all of a sudden [1]. There is an urgent need of establishment of control warning systems based on biosensors, microbial identity and its behavior to the man and environment to overcome and preventing biological threats [15]. Both threats and deterrents causes, and effects of bio-terrorism in different parts of the world in Çankaya and Kibaroğlu, in 2010.

To make a potential defense cover against bioterrorism terror a strategic shield is required with quick operating command units, surveillance, preparedness and vaccination. It can remove out fear of bioterrorism from the human community [16]. For identification of microbes, pathogens, applied epidemiology and training programs, diagnostic laboratories and a global network by various health agencies must be established among countries [17]. There are few risk assessment tools for differentiating unnatural from natural epidemics. These tools are increasingly necessary and valuable. In addition, improved scoring systems with higher sensitivity, specificity, timeliness, and wider application to biological attacks must be developed [18]. For quick responses computerized biosimulators, the trans-disciplinary partnerships of the universities might involve, and will form essential collaborations be required among the states and local health departments [18]. Certain automated reporting system based on biosensors and cameras can also access infectious disease in environment [19]. All such methods cam quickly assesses the type of microbe and its possible devastating effects in population [20]. Therefore, adequate public health preparedness for bioterrorism includes the elaboration of an agreed list of biological and chemical agents that might be used in an attack or as threats of deliberate release [21]. All efforts based on bio-safety and bio-defense is required to counterterrorism, hence all emergency departments, and the infectious disease specialists remain on alert [21]. The impact of an infectious disaster do not provide enough time for developing an effective response, hence potential counter measures remain ready and start working as soon as they find information about an infectious disaster. For finding possible and timely solutions of effects of biological agents; vulnerabilities and bio-security should review time to time and all out comes must be shared among stakeholders to strengthen the collaboration. Therefore, new systems, legislation, collaborative 


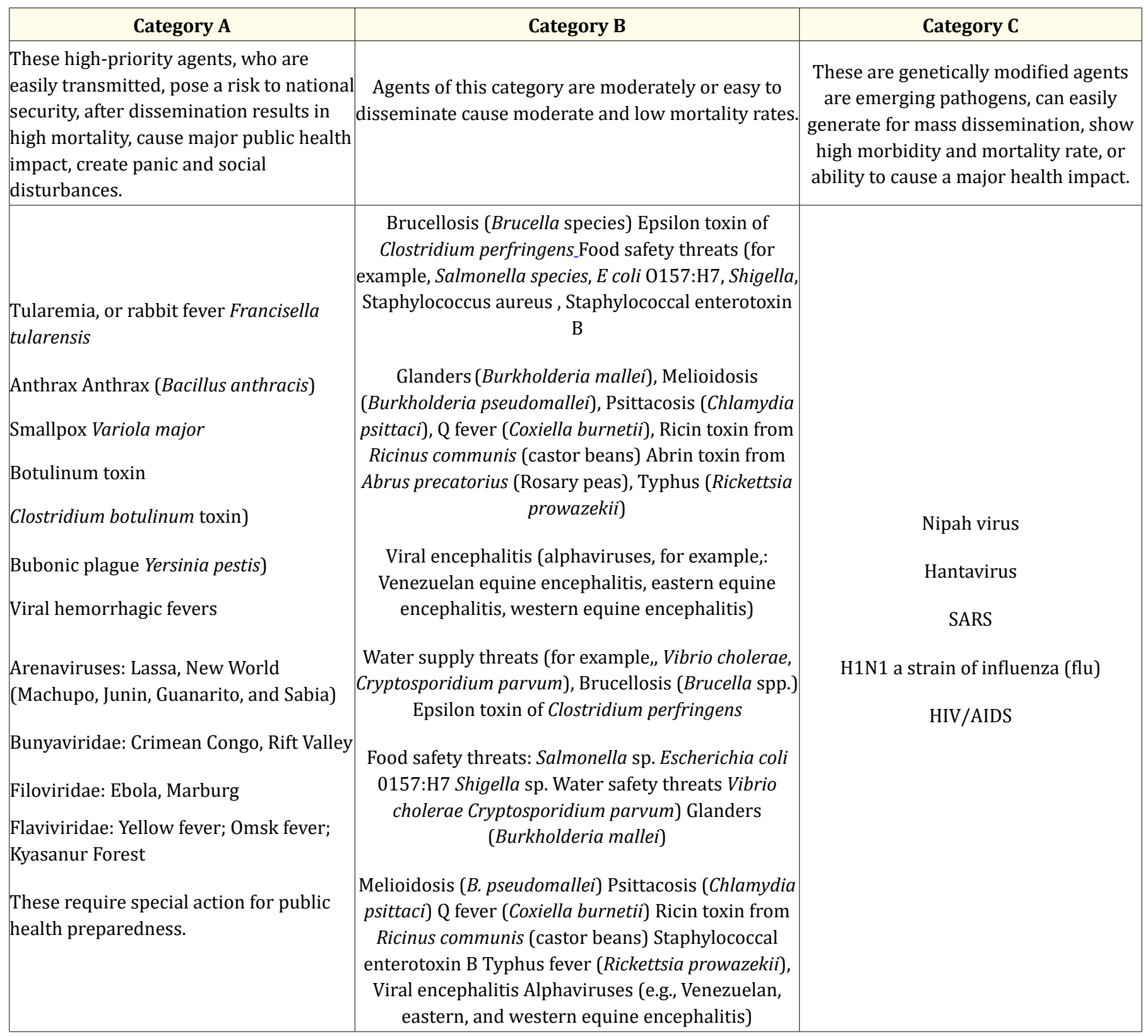

Table 1: Various categories of microbes which are used in bioweapon and effect human life.

operational models, and ways of thinking are required to effectively address the threat to global bio-security [22].

\section{Bio-surveillance and risk assessment}

For enumeration of impact of biological warfare, bio-surveillance is highly important and essential. Bio-surveillance is the sci- ence of real-time disease outbreak detection. Its principles apply to both natural and man-made epidemics (bioterrorism). The collected data from field and analyzed in laboratory could assist in early detection of a bioterrorism event include many categories of information. However, health-related data must be stored in hospi- 
tal computer systems, clinical laboratories, and in electronic health related record systems. Information from medical examiners, veterinary medical record systems and call center computers must be preserved in record-keeping systems. A speedy diagnosis and monitoring of food items, water supply systems, school attendance recording, and physiological checkup is also required [23]. There should be an emergency calling system, but it will need processing of false and real information to check the unnecessary panic. Many European countries have started disease surveillance that starts with quick identification of disease pathogens in air, monitoring of infected person and area and origin of outbreak.

For getting quick response an automated bioterrorism detection system, called RODS (Real Time Outbreak Disease Surveillance) has been deployed by Center for Biomedical Informatics, in the University of Pittsburgh's. RODS collect data from many data sources and use them to perform signal detection. It assists in assessment of possible bioterrorism event at the earliest possible moment. RODS, and other systems like it, collect data from sources including clinic data, laboratory data, and data from over-the-counter drug sales [24]. All 50 states of US have been equipped with bio-surveillance systems.

Moreover, fibre-optic tubes lined with antibodies coupled to light-emitting molecules can be specifically used for identification of specific pathogens, such as anthrax, botulinum, ricin. Similarly, ultraviolet avalanche photobodies are used to detect anthrax and other bioterrorism agents in the air [25]. The United States Department of Defense conducts global biosurveillance through several programs, including the Global Emerging Infections Surveillance and Response System [26]. Researchers are also trying to prepare devices i.e. tiny electronic chips that would contain living nerve cells and brain to warn of the presence of bacterial toxins.

Syndromic surveillance based on electronically monitoring and reporting real-time medical data can proactively identify unusual disease patterns. It also highlights the safeguarding public health and preserves the privacy of affected person [27]. There is a need to follow disease-specific, demographic, geographic, and seasonal distribution of selected bioterrorism-related conditions (anthrax, botulism, brucellosis, cholera, plague, tularemia, and viral encephalitides). Between 1992-1999 cases of Tularemia and brucellosis were the most frequently reported diseases while Anthrax, plague, western equine encephalitis, and eastern equine encepha- litis were rare as reported by National Notifiable Diseases Surveillance System [28]. There should be an increased awareness and early detection of threats facilitated by an integrated network of responsibilities and capabilities from government, academic, private, and public assets [29]. The information and technical support can remove out fears, check unnecessary antibiotic treatment, and enhance laboratory-based surveillance for bioterrorism events worldwide [10].

\section{Risk assessment of bioterrorism}

Risk Assessment of bioterrorism attacks is highly needful [30]. For this purpose fast detection systems and diagnostic decision support systems are being required for quick response to mitigate a biological warfare [31]. There is a need to early identification of agents of bio-warfare and bioterrorism [32,33]. For monitoring environmental and human health hazards animal models can be used as a surveillance tool $[34,35]$. The primary prevention level should comprise internal surveillance of potential sources of agents and terrorists. Secondary prevention activities should be directed toward breaking both the epidemic of infectious disease and that of fear and panic. Tertiary prevention should include measures for repair following the attack. This is a task mainly for mental health professionals, curing and rehabilitating those affected by the epidemic of fear and panic. In addition training programmes be organized for detecting and responding to bioterrorist attacks around the world [36]. However, for development of biological defense bioterrorism Command Center must open. Major protocols for sample intake, processing, reporting, security, testing, staffing, and quality assurance and quality control are also described [37].

Specific guidelines and recommendations for laboratory safety and risk assessment in the clinical microbiology must explore. All such information's and biological samples must be screened by sentinel laboratories can better prepare for the next biological disaster [38]. Reliable results can be obtained in a short time period using a portable biosensor by nonprofessionals owing to the simple nature of UPT-POCT operation and sample pre-treatment [39]. Analysis and evaluation of these surveillance data help public health practitioners react to important health events in a timely manner both locally and nationally [40]. Besides, biological health, both emotional and behavioral effects of bioterrorism must be studied [41]. By keeping in mind the tragic events of 9/11 in New York, risk analysis of terrorist or hostile state attack with weapons 
of mass destruction made mandatory [42]. The risk management model is demonstrated with an illustrative bioterrorism problem with notional data [42].

\section{Preparedness}

A bioterrorism event is a disaster that requires specific early preparations beyond the usual medical disaster planning. With the persistent threat of emerging infectious diseases and bioterrorism, it has become increasingly important that clinicians be able to identify the diseases that might signal the occurrence of these unusual events through a well established laboratory response network system [43]. Preparedness is highly important to counter measure terror attack made by using biological agents. Hence, in many countries laboratories are working to develop much advanced detection systems to provide early warning, identification of contaminated areas and population exposed at risk. It facilitates prompt treatment. Methods for predicting the use of biological agents in urban areas as well as assessing the area for the hazards associated with a biological attack are being established in major cities. In addition, forensic technologies which could quickly identify biological agents, its geographical origins must require. Efforts include decontamination technologies to restore facilities without causing additional environmental concerns. However, for mitigation of emerging infectious diseases and bioterrorism early detection and rapid response to bioterrorism is highly essential [44]. It will depend on close cooperation between public health authorities and law enforcement; however, such cooperation is currently lacking. National detection assets and vaccine stockpiles are not useful if local and state officials do not have access to them [45]. Government and international health organizations should develop fast responding systems, technology and resources to monitoring epidemics [37] and risk communication during bioterrorismrelated outbreaks [45].

\section{Response to bioterrorism incident or threat}

\section{Clinical detection and neutralization of microbes}

There are different methods used to detect presence of microbial war fare agents in biological samples. Bacillus anthracis in sample can be detected by blood, skin lesion swab, and spinal fluid and respiratory secretions. It is detected by measuring antibodies or toxin in blood. For diagnosis of aspergilloma or invasive aspergillosis imaging test such as chest X-ray or computerized tomography (CT) scan are used to reveal a fungal mass and confirm any sign of invasive aspergillosis and allergic bronchopulmonary aspergillosis. Respiratory secretion (sputum) test is also performed to know the presence of aspergillus filaments in specimens. Biopsy is also done to confirm invasive aspergillosis. The ideal bio-detector would identify bacterial spores (B. anthracis), vegetative forms ( $Y$. pestis or F. tularensis), a range of viruses (Venezuelan equine encephalitis and variola viruses), and toxins mainly botulinum to 300-Da saxitoxin. There are expert's suggestions available that B. anthracis spores, $Y$. pestis, F. tularensis bacilli, and variola virus require medical countermeasures within 24-48 h after exposure, must need rapid detection.

The IBAD can identify 8 BW agents in $15 \mathrm{~min}$. So far, 20 systems have been fielded, The Interim Biological Agent Detector (IBAD), a sea-based system, is a simplified version of BIDS can identify 8 BW agents in $15 \mathrm{~min}$. In BIDS systems light-addressable potentiometric pH sensor (LAPS) immunoassay system, is used to probe or activate the sensing surface. One such system is the Biological Integrated Detection System (BIDS) developed by the DoD.

Most of the current R\&D on detection of biological weapons employs nucleic acid- or antibody-based probes combined with optical, fluorescence, transduction tubes. These are based on mass spectrometry fiber-optic, microsphere-based, high-density array composed of 18 species-specific probe micro-sensors for identification of biological warfare agents. Laboratory Response Network (LRN) is a recent system that is used help hospitals, doctors, and public health officials quickly confirm a diagnosis of anthrax. ELISA is also conducted using urease as the enzyme label. In February 2011 a simulated anthrax attack code named Dark Zephyr was conducted to observe the impact of anthrax. It was about the use of anthrax vaccine for post-exposure prophylaxis in children. After considering the issue in the wake of Dark Zephyr, the National Biodefense Science Board, a federal advisory panel to HHS, decided to vaccinate the child victims of an attack. Adults exposed with would be given three doses of the vaccine, along with oral antibiotics, as post-exposure prophylaxis (PEP) under Emergency Use Authorization.

There are possibilities that terrorist groups may use one or more of a variety of agents of infectious diseases, and vast majority them are zoonoses [46]. Hence, the use of effective vaccines would likely protect lives and limit disease spread in a biological weapons 
emergency. For safety purpose licensed vaccines of anthrax and smallpox vaccine are available for vaccination [47]. Further, efforts are also going on to develop and produce vaccines for other threats, such as tularemia, Ebola virus, and Marburg virus. There are many bio-weapon disease threats may come to face in future, hence, lack of a corresponding effective vaccine, is highly required, it is a significant challenge exist to vaccinate people in an emergency.

Mass vaccination of people in pre-preparedness program provide extreme relief as these provide major prophylactic cover and reduce morbidity and mortality from infectious diseases more than any other specific medical treatment [48]. But vaccine efficacy should be checked from time to time as host-microbe interaction and the immune response to potential get decrease due to mutations. For giving an instant fight against any terror attack development of new vaccines and immune-based therapies is highly essential to check the to harm the public [48]. For neutralization of a virus or a microbial attack a successful deployment of vaccines, antibodies, and other medications in a bioweapon event are highly essential. Administration should ensure availability of viable vaccine and drugs and clinical care of affected people in extreme quarantine conditions. It can check further spread and exposure of microbial infection. For providing protection cover passive immunization also play important role. For this use of killed infectious agents could be pre-injected. However, in response to certain bioweapon attacks antibodies are taken from immune donors into nonimmune individuals. For making sizable bio-defense full length, human like glycosylated antibodies are synthesized on large scale for administration. These "borrowed" antibodies provide very a short immunity against infection but provide protection for two months. Such antibodies provide immediate protection, whereas a protective response generated by a vaccine is not immediate.

US developed a Modular Ultrasonic Lysis System for Rapid Nucleic Acid Extraction and Sample Transfer of Bacillus Spores. This is an effective response and attention providing step towards infection control and helping in large-scale vaccination or antimicrobial prophylaxis [49]. The designed molecular system is used for detection of bioterrorism agents in clinical isolates of $C$. burnetii. Method is based on constructed plasmids mainly multi-pathogens sequence containing plasmids as positive controls for universal detection of potential agents of bioterrorism [50].
Recent Covid-19 pandemic caused by SARS-CoV-2 has many features similar to a biological weapon i.e. its high transmission rate, long incubation period, airborne transmission, multiple morbidity, high mortality and lastly highly mutable and resistant to climatic factors [51]. It is correct that this China made virus has been spread form Virological Research laboratory in Wuhan. This is a well organized silent bioterror attack and spread deliberately with bad intentions by China [51] (Table 2). Coronavirus is largely targeting both urban and village human habitations and showing high infectivity and high mortality rate. Coronavirus grows in upper respiratory tract and is released in open air through sneezing and coughing by patient. Thousands of micro aerosols or small droplets suspend and virus live for two three hours in air and enter inside next host human body through inhalation of air. Among important reasons is genetic susceptibility of virus particle to changing weather conditions. Within no time virus started changing itself according to new climate. These climate induced mutations strengthen the virus and enhanced fatalities and infectivity. It has been reported that attainment of genetic variability or mutations in prevailing climatic conditions. It is a very challenging task to control such type of transmission and break the continuing chain in human population/community [50]. All these features prove that recent Covid-19 pandemic caused by SARS-CoV-2 is a bioterror attack [51]. It will need large scale surveillance to study transmission, pathogenesis, and development of immune responses, prophylaxis and vaccination [52].

\section{Conclusion}

For quick neutralization of any bioterrorism attack fast detection systems and diagnostic decision support systems which respond very fast are highly essential and needful. Risk Assessment should be done to respond such attacks in future. Government and international health organizations should develop fast responding systems, technology and resources for detection of pathogens and monitoring epidemics. Planning may involve the development of biological identification systems, training programmes for detecting and responding to bioterrorist attacks around the world. Therefore, to counter and slow down the deadly fission of microbes like radioactive bombs all safety and bio-defense technology must be developed or hired by the countries to protect the life of people. Government and international health organizations should develop fast responding systems, technology and resources to monitor- 


\begin{tabular}{|c|c|c|c|c|c|c|}
\hline Microbial agent & Clinical nature & $\begin{array}{l}\text { Incubation } \\
\text { period }\end{array}$ & Lethality & $\begin{array}{l}\text { Transmission } \\
\text { Man-man }\end{array}$ & $\begin{array}{l}\text { Possible } \\
\text { treatment }\end{array}$ & Precautions \\
\hline Pneumonic plague & $\begin{array}{c}\text { Fever, body aches, chest } \\
\text { pain and, hemoptysis and } \\
\text { slow and step wise } \\
\text { respiratory failure }\end{array}$ & $2-3$ & High & $\begin{array}{c}\text { Direct contact and } \\
\text { air exposure }\end{array}$ & $\begin{array}{l}\text { Sreptomycin, } \\
\text { gentamycin, } \\
\text { doxycycline, } \\
\text { ciprofloxicin }\end{array}$ & $\begin{array}{l}\text { Respiratory } \\
\text { isolation }\end{array}$ \\
\hline $\begin{array}{l}\text { Anthrax } \\
\text { (inhalation) }\end{array}$ & $\begin{array}{c}\text { Non specific prodrome, } \\
\text { followed by fever, dyspnea } \\
\text { and shock }\end{array}$ & $1-6$ & High & Inhalation & $\begin{array}{l}\text { Ciprofloxacin/ } \\
\text { doxycycline }\end{array}$ & $\begin{array}{c}\text { Standard } \\
\text { precautions }\end{array}$ \\
\hline Tuleremia & $\begin{array}{c}\text { Fever, coryza, headache, } \\
\text { weakness , cough, chest } \\
\text { pain, abdominal pain and } \\
\text { watery diarrhea }\end{array}$ & 2-10 days & $\begin{array}{l}\text { Moderate if } \\
\text { treated }\end{array}$ & Air and water & $\begin{array}{l}\text { Sreptomycin, } \\
\text { gentamycin, } \\
\text { doxycycline, } \\
\text { ciprofloxicin }\end{array}$ & $\begin{array}{c}\text { Standard } \\
\text { precautions }\end{array}$ \\
\hline Aerosolized ricin & $\begin{array}{c}\text { Cough respiratory } \\
\text { distress }\end{array}$ & 1-5 days & High & Inhalation & Supportive care & $\begin{array}{c}\text { Standard } \\
\text { precautions }\end{array}$ \\
\hline SARS-COV-1 and 2 & $\begin{array}{c}\text { Fever, dry cough, sepsis, } \\
\text { ARDS }\end{array}$ & 1-6 days & High & Inhalation & Vaccine & $\begin{array}{c}\text { Standard } \\
\text { precautions }\end{array}$ \\
\hline
\end{tabular}

Table 2: Microbial agents which cause acute lower respiratory syndrome/symptoms.

ing epidemics and risk communication during bioterrorism-related outbreaks. Government agencies which would be called on to respond to a bioterrorism incident would include law enforcement, hazardous materials/decontamination units and emergency medical units, if they exist. Both command centers and chemical biological incident response units must develop detect, identify, and neutralize threats, and decontaminate victims exposed to bioterror agents (CDC). High level quarantine, photo imaging detection systems must be developed to reduce risk to national security. It will also require special action for public health preparedness to minimize the deadly impact of microorganisms by making safety vaccines for immunization, antimicrobial drugs, sera, antibodies and all other prophylactic and safety measures by India. Further, to mitigate the effect of any virus attack, special microbial disease prevention centers and clinical aid centers must be established with all possible equipments and clinical aids to be required for the safety of citizens of this sovereign country. This should be included in national security advisory and priority list to create fast acting operational groups in wartime.

\section{Acknowledgements}

Author is thankful to H.O.D., Department of Zoology for research facilities.

\section{Conflict of Interest}

The authors declares no interest of conflict.

\section{Bibliography}

1. Clercq E De and Kern ER. "Handbook of Viral Bioterrorism and Biodefense". Elsevier Science; 1st edition 57.1-2 (2003): 1-152.

2. Naeem Z and Iftikhar S. "Bioterrorism, an Emerging Threat". Trends of Environmental Forensics in Pakistan (2019): 111124.

3. Atakro CA., et al. "Nurses' and Medical Officers' Knowledge, Attitude, and Preparedness Toward Potential Bioterrorism Attacks". SAGE Open Nursing 3 (2019): 5.

4. Artenstein AW. "Bioterrorism and Biodefense". Infectious Diseases (2017): 670-679.e1.

5. Green MS., et al. "Confronting the threat of bioterrorism: realities, challenges, and defensive strategies". Lancet Infectious Disease 19.1 (2019): e2-e13.

6. Clements B. "Bioterrorism preparedness coordination: an ataxic saga continues". Public Health Report 119.1 (2004): 1618. 
7. Nofal A., et al. "Knowledge and preparedness of healthcare providers towards bioterrorism". BMC Health Services Research (2021): 21.

8. Janik E., et al. "Biological Toxins as the Potential Tools for Bioterrorism". International Journal of Molecular Sciences 20.5 (2018).

9. Treadwell TA., et al. "Epidemiologic clues to bioterrorism". Public Health Report 118.2 (2003): 92-98.

10. Polyak CS., et al. "Bioterrorism-Related Anthrax: International Response by the Centers for Disease Control and Prevention". Emerging Infectious Diseases 8.10 (2002): 1056-1059.

11. Oliveira M., et al. "Biowarfare, bioterrorism and biocrime: A historical overview on microbial harmful applications". Forensic Science International 314 (2020): 110366.

12. Durodié B. "Facing the possibility of bioterrorism". Current Opinion in Biotechnology 15.3 (2004): 264-268.

13. Jończyk-Matysiak E. "Possible Use of Bacteriophages Active against Bacillus anthracis and Other B. cereus Group Members in the Face of a Bioterrorism Threat". Biomed Research International 2014 (2014).

14. Craft DW., et al. "Bioterrorism: a Laboratory Who Does It?" Journal of Clinical Microbiology 52.7 (2014): 2290-2298.

15. Ryan CP. "Zoonoses Likely to Be Used in Bioterrorism". Public Health Report 123.3 (2008): 276-281.

16. Dworkin MS., et al. "Fear of Bioterrorism and Implications for Public Health Preparedness". Emerging Infectious Diseases 9.4 (2003): 503-505.

17. Sandhu HS., et al. "A global network for early warning and response to infectious diseases and bioterrorism: applied epidemiology and training programs, 2001". American Journal of Public Health 93.10 (2003): 1640-1642.

18. McKinney WP. "Educating Health Professionals to Respond to Bioterrorism". Public Health Report 120 (2005): 42-47.

19. M'ikanatha NM. "Automated Laboratory Reporting of Infectious Diseases in a Climate of Bioterrorism". Emerging Infectious Diseases 9.9 (2003): 1053-1057.
20. O'Toole T. "Emerging illness and bioterrorism: Implications for public health". Journal of Urban Health 78.2 (2001): 396402.

21. Tegnell A., et al. "Biological weapons: Development of a matrix to evaluate the threat of biological agents used for bioterrorism". Cellular and Molecular Life Sciences 63.19 (2006): 22232228.

22. IHB - The DoD Immunization Information and Training Portal". Archived from the original on 2009-08-14 (2009).

23. "CDC Botulism - Emergency Preparedness and Response". 2019-08-19.

24. "IHB - The DoD Immunization Information and Training Portal". Archived from the original on 2009-08-14.

25. Nigam, PK and Nigam A. "Botulinism toxin". Indian Journal of Dermatology 55.1 (2010): 8-14

26. "CDC - Facts About Botulism". Archived from the original on 2017-07-03. Retrieved 2018-12-18.

27. Nordin JD., et al. "Bioterrorism Surveillance and Privacy: Intersection of HIPAA, the Common Rule, and Public Health Law". American Journal of Public Health 98.5 (2008): 802-807.

28. Chang Mh., et al. "Endemic, Notifiable Bioterrorism-Related Diseases, United States, 1992-1999”. Emerging Infectious Diseases 9.5 (2003): 556-564.

29. Budowle B., et al. "Role of law enforcement response and microbial forensics in investigation of bioterrorism". Croatian Medical Journal 48.4 (2007): 437-449.

30. Balicer RD and Wiser I. "Introduction to Bioterrorism Risk Assessment". Risk Assessment and Risk Communication Strategies in Bioterrorism Preparedness (2007): 3-17.

31. Bravata DM., et al. "Evaluating Detection and Diagnostic Decision Support Systems for Bioterrorism". Emerging Infectious Diseases 10.1 (2004): 100-108.

32. Christian MD. "Biowarfare and Bioterrorism". Critical Care 29.3 (2013): 717-756.

33. Buehler JW., et al. "Syndromic Surveillance and Bioterrorismrelated Epidemics". Emerging Infectious Diseases 9.10 (2003): 
1197-1204.

34. Neo JPS and Tan BH. "The use of animals as a surveillance tool for monitoring environmental health hazards, human health hazards and bioterrorism". Veterinary Microbiology 203 (2017): 40-48.

35. Dantas-Torres F., et al. "Human-Animal Medicine, Clinical Approaches to Zoonoses, Toxicants and Other Shared Health". Parasites Vectors 3 (2010): 20.

36. Radosavljević V and Jakovljević B. "Bioterrorism-Types of epidemics, new epidemiological paradigm and levels of prevention". Public Health 121.7 (2007): 549-557.

37. Heller MB., et al. "Laboratory Response to Anthrax Bioterrorism, New York City, 2001”. Emerging Infectious Diseases 8.10 (2002): 1096-102.

38. Wagar E. "Bioterrorism and the Role of the Clinical Microbiology Laboratory". Clinical Microbiology Review 29.1 (2016): 175-89.

39. Zhang P. "Application of UPT-POCT in Anti-bioterrorism and Biosecurity". Principles and Applications of Up-converting Phosphor Technology (2019): 211-233.

40. Hutwagner L., et al. "The bioterrorism preparedness and response Early Aberration Reporting System". Journal of Urban Health 80 (2003): i89-96.

41. Stein BD., et al. "Emotional and Behavioral Consequences of Bioterrorism: Planning a Public Health Response". Milbank $Q$ 82.3 (2004): 413-455.

42. Parnell GS., et al. "Intelligent Adversary Risk Analysis: A Bioterrorism Risk Management Model”. Risk Analysis 30.1 (2010): 32-48.

43. Pien BC., et al. "Use of Sentinel Laboratories by Clinicians to Evaluate Potential Bioterrorism and Emerging Infections". Clinical Infectious Disease 42.9 (2006): 1311-1324.

44. Koplan J and Koplan J. “CDC's strategic plan for bioterrorism preparedness and response”. Public Health Report 116 (2001): 9-16.
45. DiGiovanni C., et al. "Community Reaction to Bioterrorism: Prospective Study of Simulated Outbreak". Emerging Infectious Diseases 9.6 (2003): 708-712.

46. “CDC Smallpox Home”. 2019-02-19.

47. Ryan CP. "Zoonoses Likely to Be Used in Bioterrorism". Public Health Report 123.3 (2008): 276-281.

48. Hassani M., et al. "Vaccines for the prevention of diseases caused by potential bioweapons". Clinical Immunology 111.1 (2004): 1-15.

49. Moran GJ., et al. "Biological terrorism". Infectious Disease Clinics of North America 22.1 (2008): 145-187.

50. Charrel RN., et al. "Multi-pathogens sequence containing plasmids as positive controls for universal detection of potential agents of bioterrorism". BMC Microbiology 4 (2004): 21.

51. Chen Y and Li L. "SARS-CoV-2: virus dynamics and host response". Lancet Infectious Disease 20.5 (2020): 515-516.

52. Upadhyay R K. "Corona Virus Generated Pathogenesis, Antigenicity, Neurovirulence, and Host Immune Responses". Acta Scientific Microbiology 4.6 (2021): 53-69.

\section{Volume 4 Issue 7 July 2021}

C) All rights are reserved by $\mathbf{R} \mathrm{K}$ Upadhyay. 